IP Periodica Polytechnica Chemical Engineering

61(3), pp. 206-215, 2017

https://doi.org/10.3311/PPch.9679

Creative Commons Attribution (i)

RESEARCH ARTICLE

\section{Study of Ceramic Membrane from Naturally Occurring-Kaolin Clays for Microfiltration Applications}

\author{
Sonia Bouzid Rekik ${ }^{1,2^{*}}$, Jamel Bouaziz ${ }^{1}$, Andre Deratani², \\ Semia Baklouti ${ }^{3}$
}

Received 29 June 2016; accepted after revision 19 December 2016

\section{Abstract}

The focus of this work is to assess the quality of porous membranes prepared from naturally occurring kaolin clays and to evaluate the performance of tubular ceramic membranes treating integrated raw effluents from seafood industry. This material has been chosen due to its natural abundance, its non-toxicity, low cost and its valuable properties. The preparation and characterization of porous tubular ceramic membranes, using kaolin powder with and without corn starch as poreforming agent, were reported. SEM photographs indicated that the membrane surface was homogeneous. The effects of material compositions, additives and the relatively lower sintering temperature, ranging from $1100^{\circ}$ to $1250^{\circ} \mathrm{C}$, on porosity, average pore size, pore-size distribution and mechanical strength of membranes have been investigated. A correlation between microstructure and mechanical properties of membranes has been discussed. The performance of the novel ceramic membranes thus obtained was determined by evaluating both the water permeability and rejection. The obtained membrane was used to treat cuttlefish effluents generated from the conditioning seawater product industry which consumes a great amount of water. Cross-flow microfiltration was performed then, in order to reduce the turbidity and chemical oxygen demand (COD).

\section{Keywords}

ceramic tubular membrane, kaolin-clays, sintering, filtration, cuttlefish effluent

\footnotetext{
${ }^{1}$ Laboratory of Industrial Chemistry National School of Engineering, University of Sfax, BP 1173,3038 Sfax, Tunisia,

${ }^{2}$ European Institute of Membranes (IEM), University of Montpellier 2, Place E. Bataillon, 34095 Montpellier Cedex 5, France

${ }^{3}$ Laboratory of Materials Engineering and Environment, National School of Engineering, University of Sfax, BP 1173, 3038 Sfax, Tunisia

*Corresponding author, e-mail: bouzidsonia@gmail.com
}

\section{Introduction}

Water pollution is one of the most important crises in modern times because water is the most important basis of life. There is much current interest in the application of microfiltration and ultrafiltration membranes in separation procedures because of their potential for the treatment of large quantities of wastewater [1-5]. This is a successful way to solve water pollution crisis and to maintain the environment wellness.

The use of ceramic membranes has many advantages such as high thermal and chemical stability, pressure resistance, long lifetime, good resistance to fouling, and ease of cleaning [6-7]. Unfortunately, ceramic membrane fabrication, even though commercially available, still remains highly expensive from a technical and economic point of view due to the use of expensive powders such as alumina [8-10], zirconia, titania and silica [11, 12].

Recently, the development of low cost ceramic membranes based on natural materials such as apatite powder [13], natural raw clay [14-16], graphite [17], phosphates [18,19], dolomite, kaolin [20-24] and waste materials such as fly ash [25-29], appeared as an efficient solution to treat waste water at a low cost. The properties of the ceramic membranes are mainly determined by their composition, the pore-former content and the sintering temperature.

MF is a membrane process for concentration, purification, and fractionation in diverse fields such as food, textile, pharmacy, chemical, paper, and leather industries. MF is often used to remove particles, microorganisms, and colloidal materials from suspensions [30-32].

Fouling would reduce productivity and potentially shorten membrane life. To understand the mechanisms of fouling, some researchers proposed various models to analyze and predict the flux decline behavior during filtration of macromolecular solutions, among them the resistance-in-series model. According to this model, the flux decline is due to the combined effects of irreversible membrane fouling which is not easy to remove $[33,34]$ but with reversible fouling, rinsing with clean water can solve the problem. The main factors that influence fouling are the physicochemical properties of the membrane, feeding solution and operating conditions. 
According to this context, this study is related to the elaboration of tubular ceramic membranes using kaolin clays (chemical structure: $\left.\mathrm{Al}_{2} \mathrm{O}_{3} \cdot 2 \mathrm{SiO}_{2} \cdot 2 \mathrm{H}_{2} \mathrm{O}[35,36]\right)$. Corn starch powder was added as pore-forming agent to produce sufficient porosity with acceptable mechanical property. Corn starch is a natural biopolymer that consists of carbon, hydrogen and oxygen. Besides, it is cheap, non toxic and environmental friendly. The porous structure takes place when the starch is burned out during the sintering process and leaves a pore in the membrane body.

The properties of the porous membranes formed were discussed as a function of sintering temperature in order to optimize the preparation conditions. Their structural and functional properties are determined by different techniques. The most important parameters used in the characterization of these substrates are: surface and internal morphology, mean pore size, pore size distribution, porosity and water permeability. Mechanical and chemical stability study of the membrane is also performed to verify its application in highly corrosive medium. The prepared microfiltration membranes were used for the treatment and the decoloration of cuttlefish effluent. Additionally, the effect of operating parameters such as transmembrane pressure, on the permeate flux and the fouling resistance are studied for microfiltration application.

\subsection{Resistance fouling theory}

The volume flux in a pressure driven membrane process depends on the hydraulic resistance of the used membrane and the pressure drop over the membrane. This is generally expressed by the following formula:

$$
J w=\Delta P / \eta w \mathrm{Rm}
$$

where, Rm is the intrinsic hydraulic resistance of the membrane and $\eta w$ is the viscosity of water.

The permeate flux (Js) after filtration of the solution can be expressed by the resistance-in-series model [34].

$$
J s=\Delta P / \eta s \mathrm{Rt}
$$

in which $\eta_{s}$ is the permeate viscosity and $R_{t}$ is the total resistance that can be defined as:

$$
R t=R m+R p+R f
$$

where, $\mathrm{Rp}$ is the resistance due to polarization layer considered as reversible fouling (polarization concentration which can be removed by water) and $\mathrm{Rf}$ is the resistance caused by irreversible fouling.

Experimentally, the intrinsic membrane resistance Rm was calculated by measuring the pure water flux Jw and viscosity $\eta w$.

Total resistance Rt was estimated from the solution flow rates under operating conditions using Eq. (4):

$$
R t=\Delta P / \eta s J_{S}
$$

Resistance, due to irreversible fouling $\mathrm{Rf}$ is determined from the pure water flux J'w through the membrane after processing and rinsing with distilled water for $10 \mathrm{~min}$ :

$$
R f=\left(\Delta P / \eta w J^{\prime} w\right)-R m
$$

This enables calculation of the resistance due to the concentration polarization Rp from Eq. (3). In order to obtain the resistance values in $\mathrm{m}^{-1}$ all variables used the SI units.

\section{Materials and methods \\ 2.1 Materials}

In this study, both the supports and membranes were prepared from clay. The clay used in the present study is a kaolin Codex, it was recommended by the L.P.M Cerina (Laboratoire des Plantes Medicinales, Tunisia). Corn starch powder was used as a pore former.

\subsection{Powder characterization}

The chemical composition of the kaolin powder was determined by spectroscopic techniques, as Xray fluorescence for metals and by atomic absorption for alkaline earth metals.

Phase identification was performed by XRD analysis (Philips $\mathrm{X}^{\prime}$ Pert X-ray) diffractometer) with $\mathrm{Cu} \mathrm{K} \alpha$ radiation $(\lambda=1.5406$ $\mathrm{A}^{\circ}$ ), and the crystalline phases were identified by reference to the International Center for Diffraction Data cards.

Thermogravimetric analysis (TG) and differential thermal analysis (DTA) were carried out from ambient temperature to $1300^{\circ} \mathrm{C}$ at a rate of $10^{\circ} \mathrm{C} \mathrm{min}^{-1}$ under air, using a setaram SETSYS Evolution 1750.

The particle size distributions of kaolin were determined by the Dynamic Laser Scattering (DLS) technique using water as dispersing medium (Mastersizer 2000, Malvern Instruments).

The powder morphology as well as the microstructure formed in the sample was determined by SEM images obtained using a Hitachi scanning electron microscope.

\subsection{Membranes elaboration}

The elaboration of membranes implies the following sequence of operations:

- preparation of a plastic ceramic paste;

- shaping by extrusion;

- Consolidation by thermal treatment.

The process of the ceramic preparation was described in Fig. 1. Porous tubular membranes were fabricated from a mixture of kaolin and starch powders. The selected composition of powders used for the plastic paste preparation was $90 \mathrm{wt}$. \% kaolin and 10 wt. \% starch as a plasticizer. The powder mixture was aged with a progressive addition of water to obtain a plastic paste with a good homogeneity and to allow the shaping. Subsequently, the paste was left for $24 \mathrm{~h}$ under a high humidity to improve its rheological property. After that, an extrusion 
technique is used to form some tubular samples. For good drying of these tubular samples, they are placed at room temperature on rotating aluminum rolls during $24 \mathrm{~h}$ to ensure a homogenous drying and to avoid twisting and bending.

Finally, a thermal treatment was carried out in an automatic and programmable furnace (Type 30400) at different final temperatures. Two steps have been determined. Subsequently, the membrane was heated up to $400^{\circ} \mathrm{C}$ for $2 \mathrm{~h}$ at a heating rate of $2^{\circ} \mathrm{C}$ min- 1 in order to eliminate the organic additive used as pore-forming agent. In a second step, the membrane was sintered at a temperature ranging from 1100 to $1250{ }^{\circ} \mathrm{C}$ with a ramping rate of $5^{\circ} \mathrm{Cmin}^{-1}$ in order to avoid the formation of cracks during sintering of the samples. The final temperature was kept constant for $1 \mathrm{~h}$. After that, the consolidated support was allowed to cool until the environmental temperature was reached.

The temperature-time schedule not only affects the pore diameters and porous volume of the final product but also allows obtaining the final morphology and mechanical strength. Tubular membranes were elaborated with external/internal diameter of $16 / 11 \mathrm{~mm}$ and the length of $150 \mathrm{~mm}$.

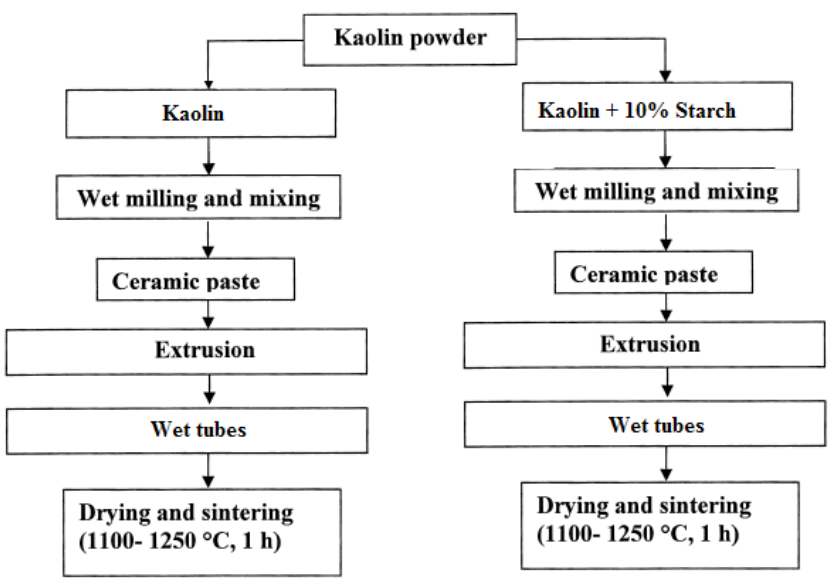

Fig. 1 Schematic diagram describing the procedures, used in this work, for membrane preparation

\subsection{Membranes characterization}

The evolution of densification and surface quality of the membranes sintered at different temperatures were determined by scanning electron microscopy.

Porosity and pore size distribution were measured by mercury porosimetry. This technique relies on the penetration of mercury into a membrane's pores under pressure [21, 23, 37]. The intrusion volume is recorded as a function of the applied pressure and then the pore size was determined.

The mechanical resistance tests were performed using the three points bending method (LLOYD Instrument) to control the resistance of the membranes fired at different temperatures.

The corrosion tests were carried out using aqueous solutions of nitric acid $(\mathrm{pH}=2.5)$ and sodium hydroxide $(\mathrm{pH}=12.5)$ at 45 and $80^{\circ} \mathrm{C}$, respectively. All the samples were ultrasonically rinsed in distilled water, dried at $110^{\circ} \mathrm{C}$ and stored in a dryer. The degree of corrosion was characterized by the percentage of the weight loss.

\subsection{Filtration pilot}

The laboratory pilot used for the filtration experiments was equipped with a cross-flow filtration system implementing tubular ceramic membrane of $15 \mathrm{~cm}$ length. The tubular membrane was placed in a stainless steel carter. The transmembrane pressure (TMP) can reach 6 bars. It was controlled by an adjustable valve on the retentate side. Temperature was kept at $25^{\circ} \mathrm{C}$ by a thermal exchange system. The membrane was conditioned by immersion in pure deionized water for a minimum of $24 \mathrm{~h}$ before filtration tests. The determination of the water membrane permeability was performed with distilled water.

\subsection{Effluent characterization}

Wastewater samples were taken from the effluents produced by a sea-product freezing factory located in Sfax, Tunisia. The cuttlefish washing waters were characterized by a high organic load and a strong salinity [3]. The dark color in this effluent was due to the presence of sepia ink (containing melanin) as suspension particles [38]. The characterization by transmission electrons microscopy revealed that these granules of "melanin" are spheres with diameter values ranging from 56 to $161 \mathrm{~nm}[18,39]$.

A large number of analyses were conducted on each sample and the following parameters were measured: turbidity, Chemical Oxygen Demand (COD), temperature and conductivity.

\section{Results and discussion}

\subsection{Characterization of the starting materials}

The chemical composition of kaolin is given in Table 1, where the main impurities are $\mathrm{CaO}, \mathrm{K}_{2} \mathrm{O}, \mathrm{TiO}_{2}$ and $\mathrm{Fe}_{2} \mathrm{O}_{3}$. It reveals that the major components were silica $\left(\mathrm{SiO}_{2}: 47.85 \%\right)$ and aluminium oxide $\left(\mathrm{Al}_{2} \mathrm{O}_{3}: 37.60 \%\right)$.

Table 1 Chemical composition of the used kaolin (wt \%).

\begin{tabular}{lllllllll}
\hline & $\mathrm{SiO}_{2}$ & $\mathrm{Al}_{2} \mathrm{O}_{3}$ & $\mathrm{Fe}_{2} \mathrm{O}_{3}$ & $\mathrm{MgO}$ & $\mathrm{K}_{2} \mathrm{O}$ & $\mathrm{CaO}$ & $\mathrm{TiO}_{2}$ & LOI* $^{*}$ \\
\hline Kaolin(\%) & 47.85 & 37.60 & 0.83 & 0.17 & 0.97 & 0.57 & 0.74 & 11.27 \\
\hline
\end{tabular}

*LOI: Loss on Ignition at $1000^{\circ} \mathrm{C}$

Phase identification is of great importance before any membrane manufacturing. Fig. 2 presents the XRD patterns of the raw and thermally treated kaolin clay. Before applying heat treatment, it can be seen that kaolinite $(\mathrm{K})$ was the major mineral component with a small amount of quartz (Q) and illite (I) impurities. No other components were observed, because the impurities are so tiny (see Table 1) and most of them are probably incorporated into the crystal structure of kaolinite. After calcinations of the sample at $600^{\circ} \mathrm{C}$, all the peaks in the 
diffractogram due to kaolinite disappeared. This is due to the transformation of kaolinite to amorphous metakaolinite. On the contrary, the peaks of quartz and illite did not change which means the kaolinite phase is only concerned by the thermal treatment at $600^{\circ} \mathrm{C}$. At a temperature of $1,250^{\circ} \mathrm{C}$, peaks of illite (I) disappeared too, whereas peaks of mullite (M) appeared due to the transformation of metakaolinite. The quartz (Q) peaks remained unchangeable in the diffractogram which confirms the thermal stability of this phase.

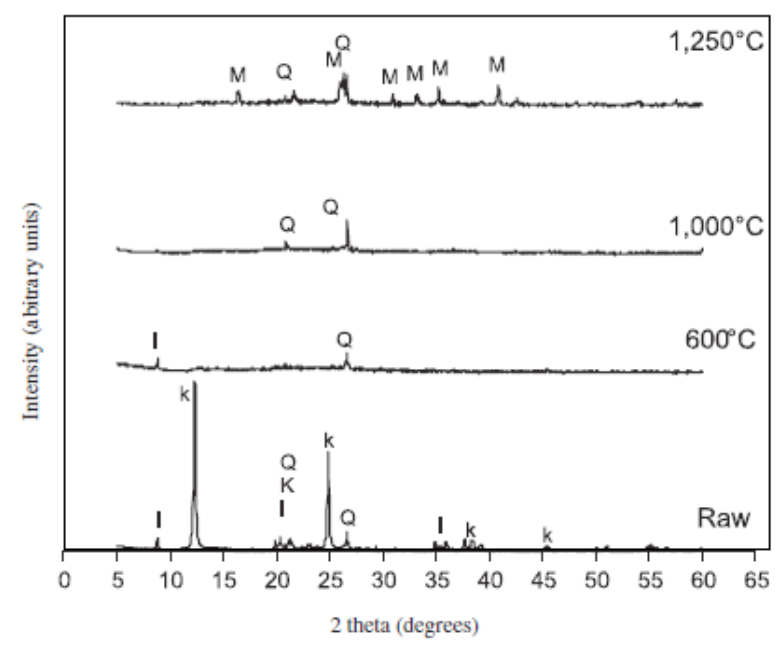

Fig. 2 XRD pattern of the pure kaolin before and after heat treatment ( $\mathrm{K}=$ Kaolinite; $\mathrm{Q}=$ Quartz; $\mathrm{I}=$ Illite; $\mathrm{M}=$ Mullite)

The particle size distribution of kaolin was determined by the Dynamic Laser Scattering (DLS) technique. This method gave an average particle size in the order of $4 \mu \mathrm{m}$.

The scanning electron microscopy (SEM) examination of clay powder presented in Fig. 3 indicates that the clay powder is characterized by a platelet-like structure typical of lamellar clays.

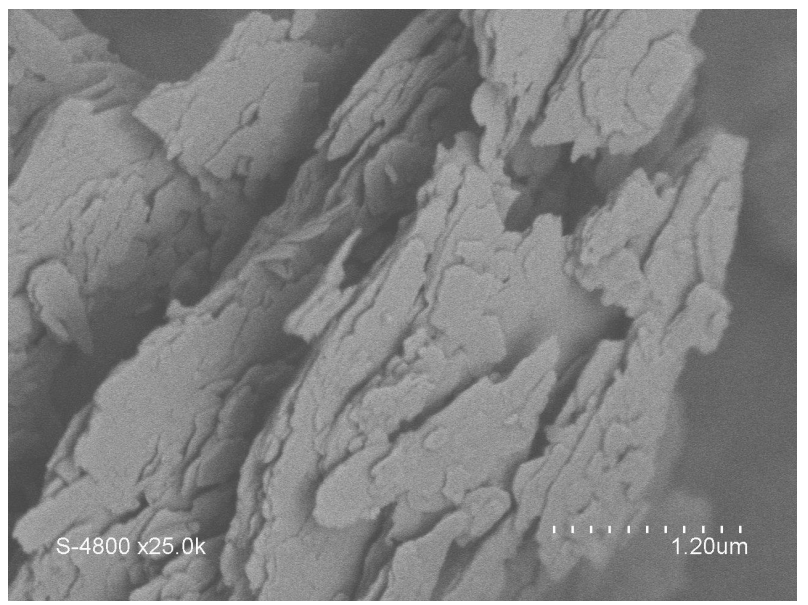

Fig. 3 SEM micrograph of the kaolin powder

A total weight loss is observed by TGA to be about $12.5 \%$ of kaolin (Fig. 4). In fact, the weight loss consists of two distinct stages: the first one is considered as a slight weight loss between room temperature and $150^{\circ} \mathrm{C}$, because of the dehydration of the kaolin-clay. The second mass loss detected between about 400 and $700^{\circ} \mathrm{C}$ is mainly due to the phenomenon of dehydroxylation of kaolinite confirmed by DTA (Fig. 5) which shows an endothermic peak at $580^{\circ} \mathrm{C}$ leading to the transformation of kaolinite to metakaolinite. A third stage, which is characterized by an exothermic reaction, appeared at about $980^{\circ} \mathrm{C}$ without any weight loss. The exothermic peak corresponds to the metakaolin-mullite transformation [40].

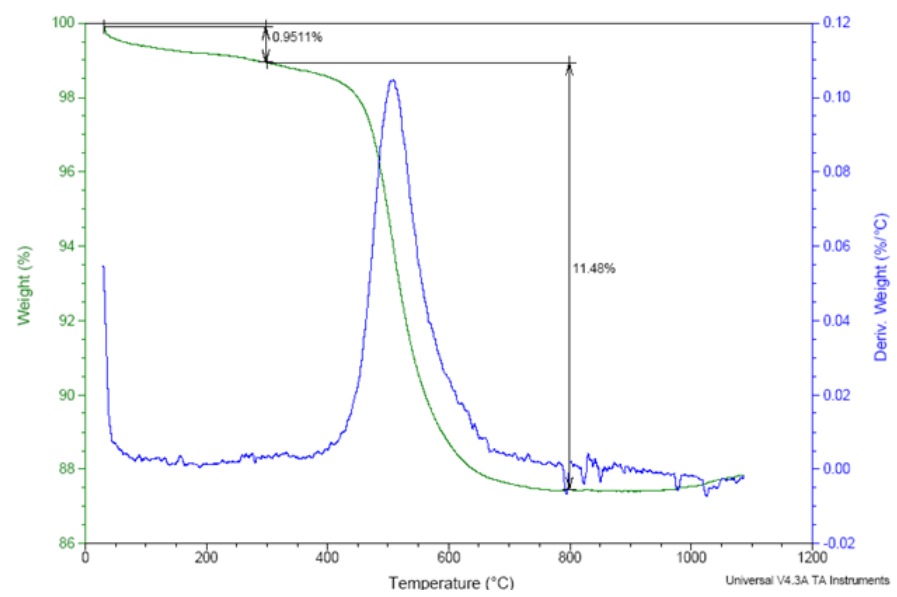

Fig. 4 TGA-DTG data of the kaolin powder

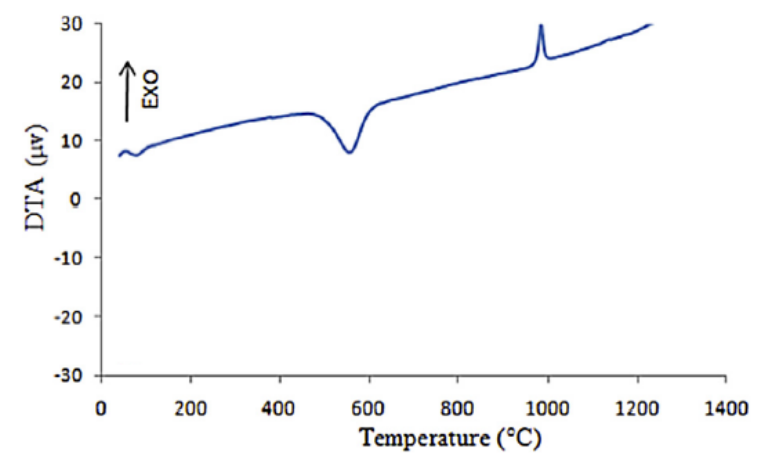

Fig. 5 DTA curve of the kaolin powder

\subsection{Characterization of the membranes}

For the development of high-quality membranes, the following properties are of major importance: pore size distribution, porosity, surface texture, mechanical properties and chemical stability.

\subsubsection{Scanning electron microscopy (SEM)}

Fig. 6 illustrates SEM pictures for the membrane sintered at the four different temperatures considered in this work. The optimal sintering temperature was determined by comparing the texture of the different obtained samples.

The ceramic substrates sintered at lower temperature $\left(1100^{\circ} \mathrm{C}\right.$ and $1150^{\circ} \mathrm{C}$ ) show highly porous structure. Below $1100{ }^{\circ} \mathrm{C}$, the presence of intergranular contacts are detected which are large enough to ensure ceramic cohesion (beginning of sintering). 
The membrane sintered at $1200^{\circ} \mathrm{C}$ and $1250^{\circ} \mathrm{C}$ are more consolidated due to the fact that for sintering temperatures over $1200{ }^{\circ} \mathrm{C}$, the particles agglomerate together creating more dense ceramic body. As a result the porosity of the membrane decreases with an increase in sintering temperature.

The obtained results (Fig. 7) show that the starch addition to kaolin has a positive effect on the porosity of membranes compared to those prepared from kaolin alone. More pores can be observed when starch corn is added to the composition, which leads to more porous structure.
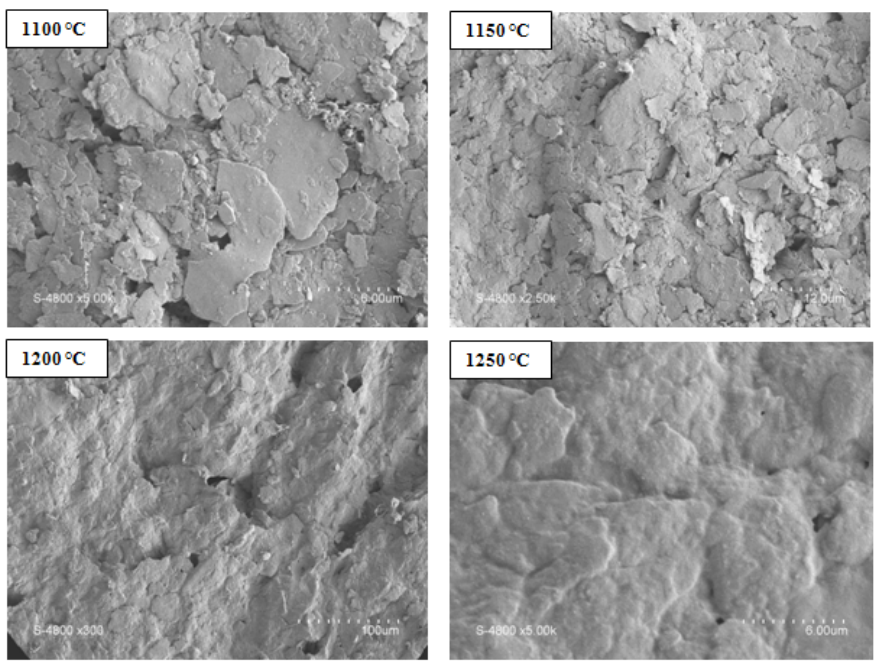

Fig. 6 SEM of membranes sintered at different temperatures
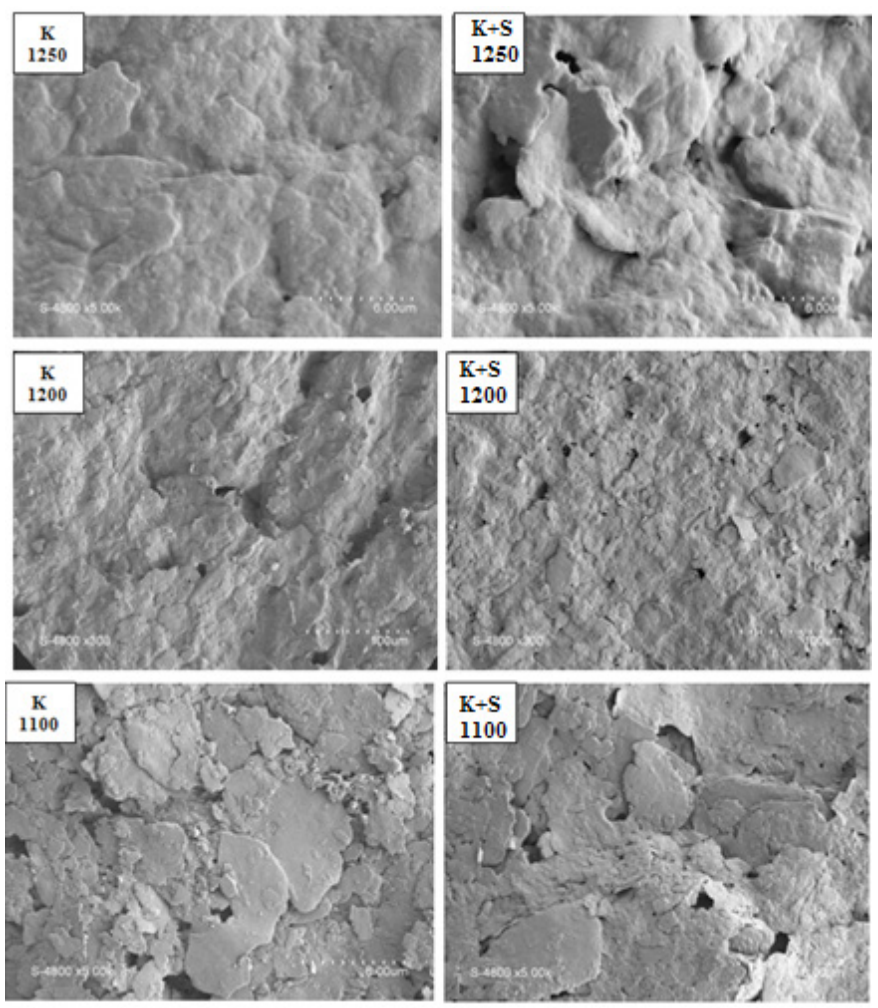

Fig. 7 SEM micrographs of kaolin and kaolin $+10 \mathrm{wt} \%$ starch samples

\subsubsection{Mercury porosimetry}

The evolution of the membrane characteristics as a function of the sintering temperature is shown in Fig. 8. The evolution of the average pore diameter and the porosity reveals that the porosity decreases from 44 to $27 \%$ between $1150^{\circ} \mathrm{C}$ and $1250^{\circ} \mathrm{C}$, while the pore diameter increased from 0.41 to $0.73 \mu \mathrm{m}$. This behavior corresponds to an opening of the pores in the same time as a material densification occurring when the temperature increases [24, 28, 41, 42].

Moreover, it can be said that both the mean average pore size and the porous volume are closely related to the preparation method. The obtained results show that the starch addition to kaolin has a positive effect on the porosity ratio of membranes compared to those prepared from kaolin alone. For example, the kaolin membrane had a porosity ratio of $27 \%$ and an average pore size of about $0.73 \mu \mathrm{m}$, whereas the kaolin $+10 \mathrm{wt} \%$ starch $(\mathrm{K}+\mathrm{S})$ membrane had a porosity ratio of $36 \%$ and an average pore size of about $1.41 \mu \mathrm{m}$, for samples sintered under the same conditions ( at $1250^{\circ} \mathrm{C}$ for 1 hour). As the corn starch burn out during sintering process, it will leave a pore in the sintered body which contributed to apparent porosity.
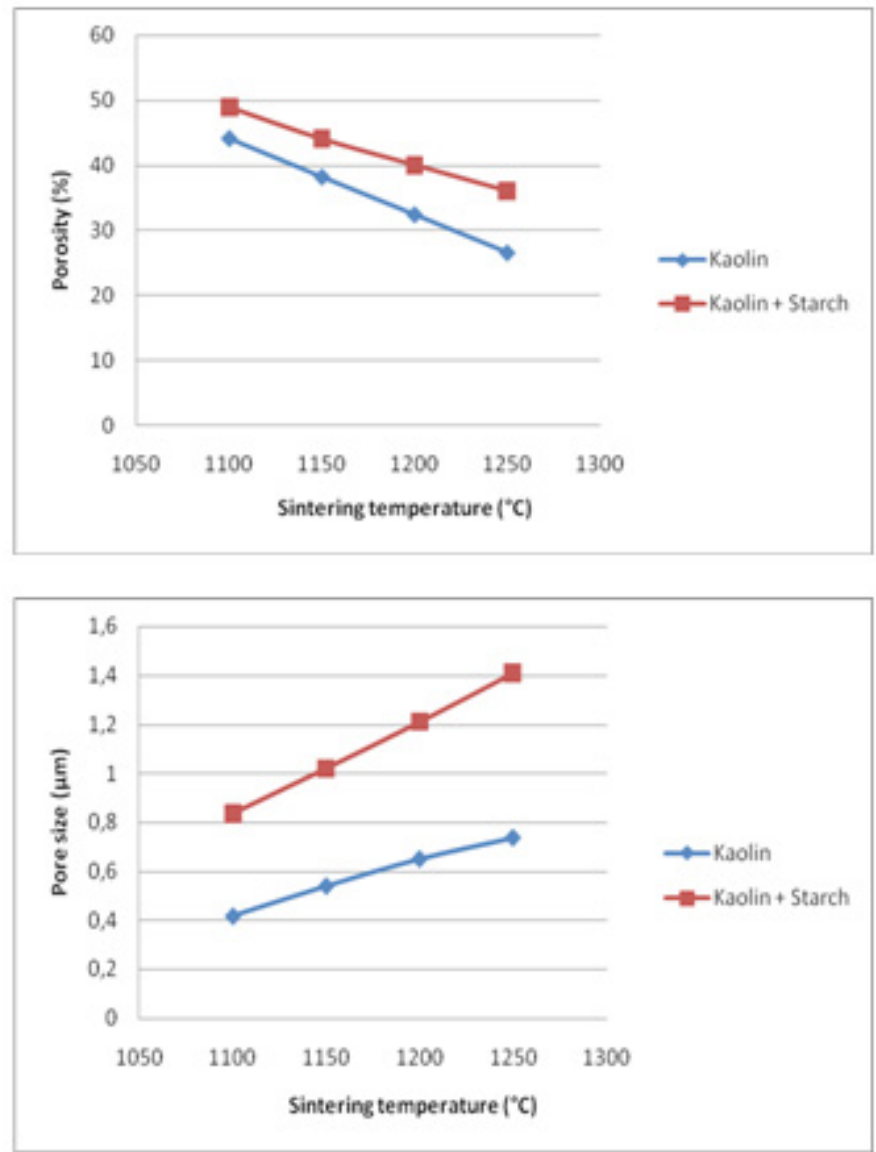

Fig. 8 Effect of sintering temperature on average pore size and porosity of samples prepared from kaolin $(\mathrm{K})$ and kaolin $+\operatorname{starch}(\mathrm{K}+\mathrm{S})$ 
The pore size distribution curves of specimens sintered at $1250^{\circ} \mathrm{C}$, for kaolin $(\mathrm{K})$ and kaolin $+10 \%$ starch $(\mathrm{K}+\mathrm{S})$, are illustrated in Fig. 9. As it can be deduced from this figure, the pore size distribution of the membrane is a single (mono modal) distribution. This is a clear indication that the samples have a uniform pore size distribution.

The average pore diameters of membranes are determined to be $0.4,0.70,0.8$ and $1.41 \mu \mathrm{m}$ for membranes (Kaolin and Kaolin+ Starch) sintered at $1100{ }^{\circ} \mathrm{C}, 1250{ }^{\circ} \mathrm{C}$ respectively corresponding to the micro-filtration range.
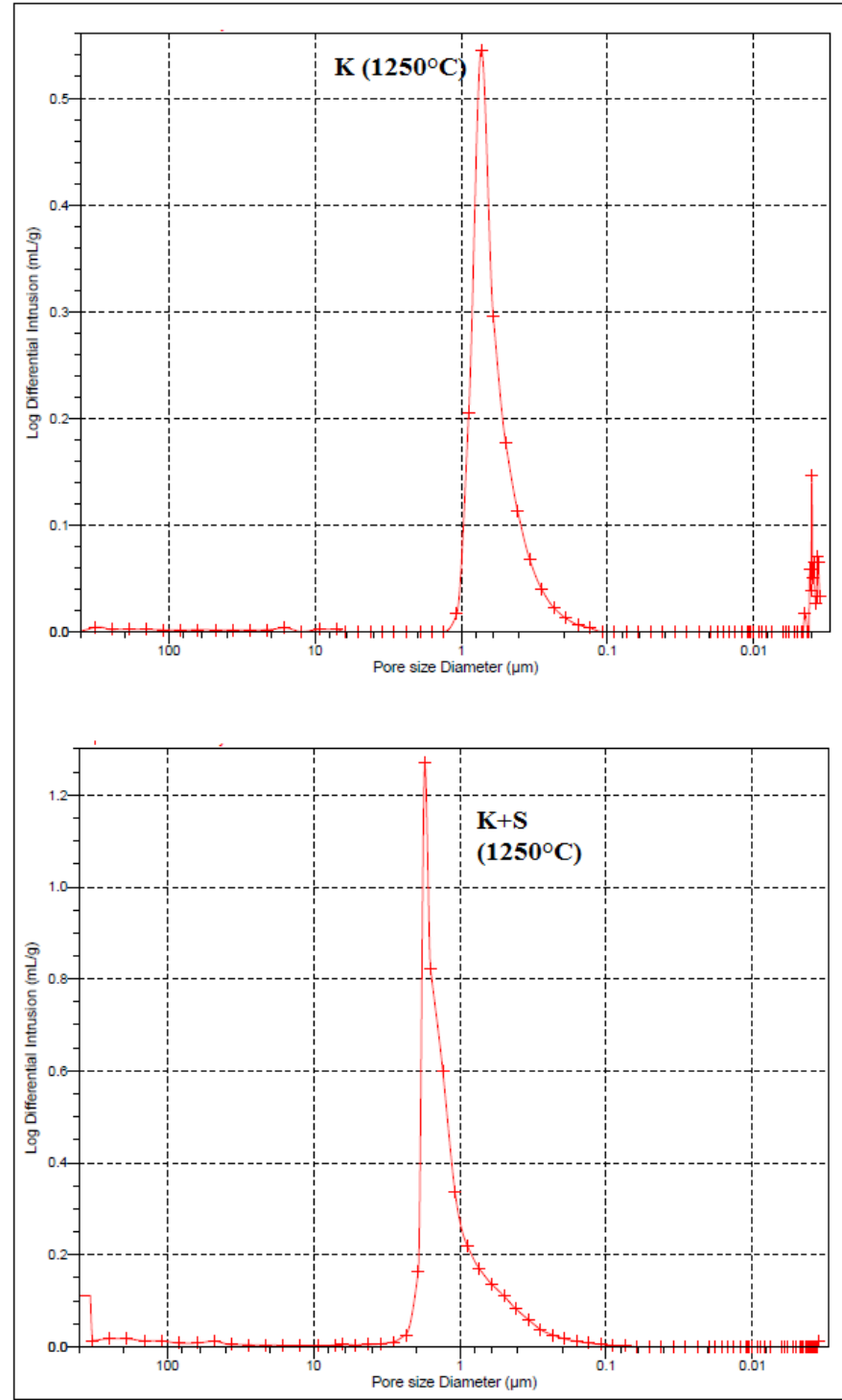

Fig. 9 Pore size distribution of samples prepared from kaolin and kaolin + starch sintered at $1250^{\circ} \mathrm{C}$ for 1 hour

\subsubsection{Mechanical resistance}

Fig. 10 shows the variation of tensile strength with sintering temperatures. In accordance with the SEM pictures and the porosity values, the increase of the sintering temperature is accompanied with a densification phenomenon and consequently an increase in the tensile strength from $4 \mathrm{MPa}$ at 1000 ${ }^{\circ} \mathrm{C}$ to $28 \mathrm{MPa}$ at $1250^{\circ} \mathrm{C}$ for membranes prepared from kaolin.
As shown in Fig. 10, the flexural strength values of the porous kaolin samples without pore former addition were higher than those of porous kaolin + organic additive samples. This figure shows that the flexural strength is closely related to the total porosity ratio which is in turn sintering temperature-dependent. For example, flexural strength was $28.41 \mathrm{MPa}$ at a porosity of $27 \%$ and an average pore size of $0.73 \mu \mathrm{m}$, whereas flexural strength was about $21 \mathrm{MPa}$ for $\mathrm{k}+\mathrm{S}$ membranes having a porosity ratio of $36 \%$ and an average pore size of $1.41 \mu \mathrm{m}$. Both $\mathrm{K}$ and $\mathrm{K}+\mathrm{S}$ supports were sintered at $1250^{\circ} \mathrm{C}$ for 1 hour.

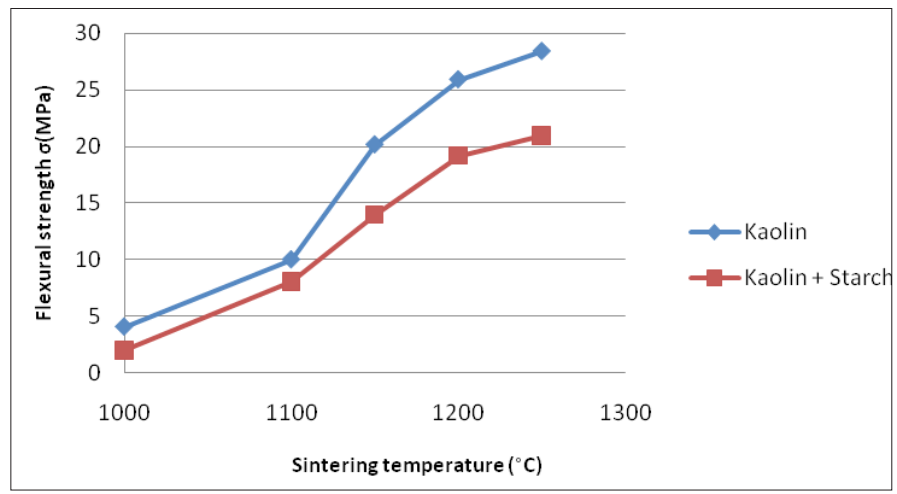

Fig. 10 Flexural strength as a function of sintering temperature for kaolin (k) and kaolin $+10 \mathrm{wt} \%$ starch $(\mathrm{k}+\mathrm{S})$ samples

\subsubsection{Choice of the membrane}

The prepared membranes sintered at $1250^{\circ} \mathrm{C}$ offer a better mechanical strength $(28 \mathrm{MPa})$. Such resistance is high enough to achieve filtration. Thus, membrane prepared from kaolin alone and sintered at $1250^{\circ} \mathrm{C}$ for 1 hour (average pore diameter of $0.73 \mu \mathrm{m}$ and $27 \%$ of porosity) was retained for corrosion tests and filtration study.

\subsubsection{Chemical resistance}

The weight loss due to the corrosion by acids and alkali is shown in Fig. 11. It can be seen that the membrane shows a better acid corrosion resistance, since its mass loss is much lower than those of membranes after alkali corrosion. Therefore, the observed results in weight loss during corrosion tests suggest that the prepared membrane possesses a good chemical corrosion resistance and it is suitable for applications involving acidic and basic media [42].

\subsubsection{Determination of membrane permeability}

The membrane was initially characterized by the determination of water permeability. It can be seen that the pure water flux increases linearly with increasing the applied pressure (Fig. 12). Pure water permeability was determined from the slope of the linear variation of flux $\left(1 / \mathrm{h} \mathrm{m}^{2}\right)$ versus the applied pressure. The membrane permeability was found to be equal to 20 1/h.m².bar. 


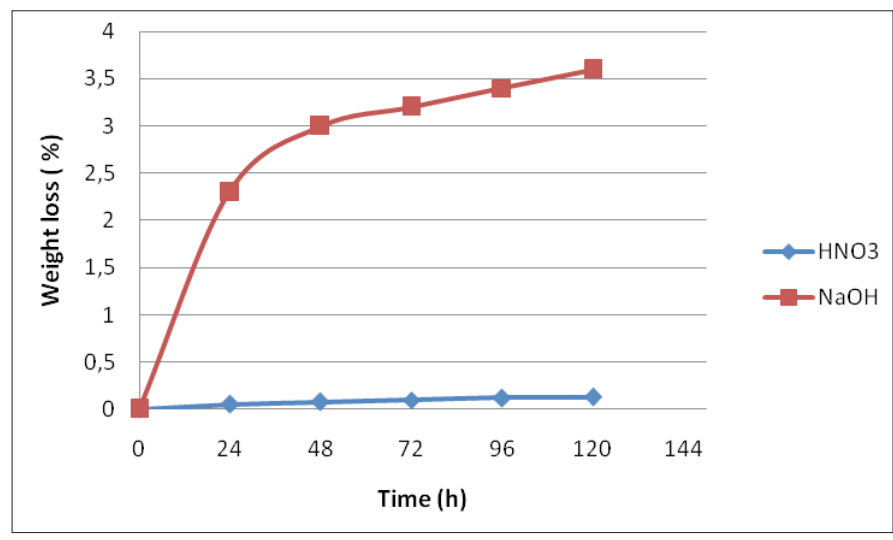

Fig. 11 Weight loss of membranes in nitric acid $\left(45^{\circ} \mathrm{C}\right)$ and soda solutions $\left(80^{\circ} \mathrm{C}\right)$ as a function of time

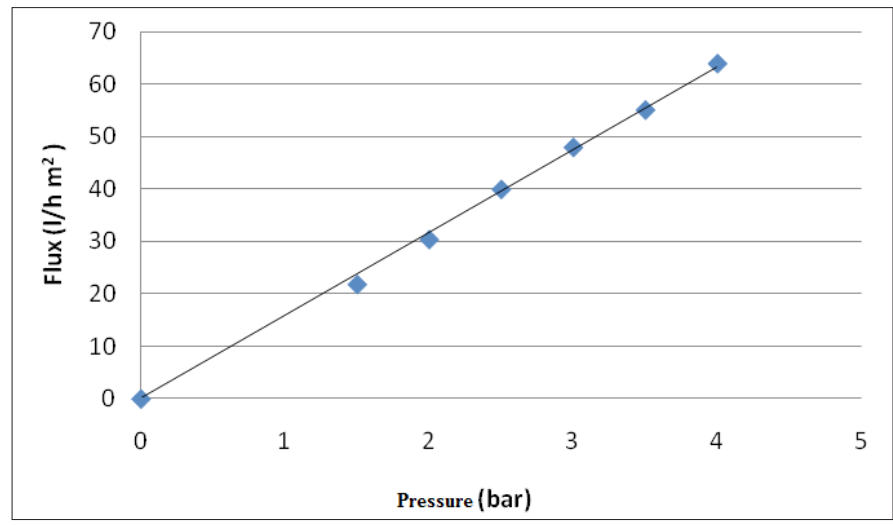

Fig. 12 Pure water flux versus operating pressure

\subsection{Application to the treatment of the cuttlefish effluents}

The elaborated membranes have been applied to the cuttlefish effluents treatment. Fig. 13 gives the variation of permeate flux with transmembrane pressure after 2 hours of filtration at $25^{\circ} \mathrm{C}$. Permeate flux increased linearly with transmembrane pressure until 4 bar and then became pressure independent. This behaviour can be explained by the formation of a concentrated polarization layer. Beyond 4 bar, the flux value is about 25 l/h.m².

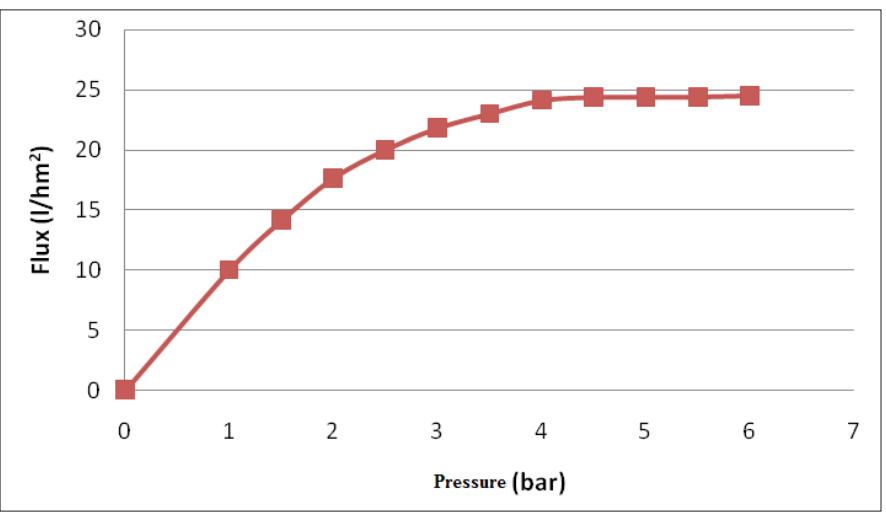

Fig. 13 Variation of the permeate flux vs transmembrane pressure
On the other hand, the variation of the permeate flux with time at different transmembrane pressures (TMP) from 2 to 4 bar shown in Fig. 14 provides information of how the membrane works. The flux decreases slightly from 43 to $201 / \mathrm{h} . \mathrm{m}^{2}$ during 60 min when operated at 3 bar TMP. Then it levels off at a constant value over time. The flux evolution corresponds to a decline of about $54 \%$.

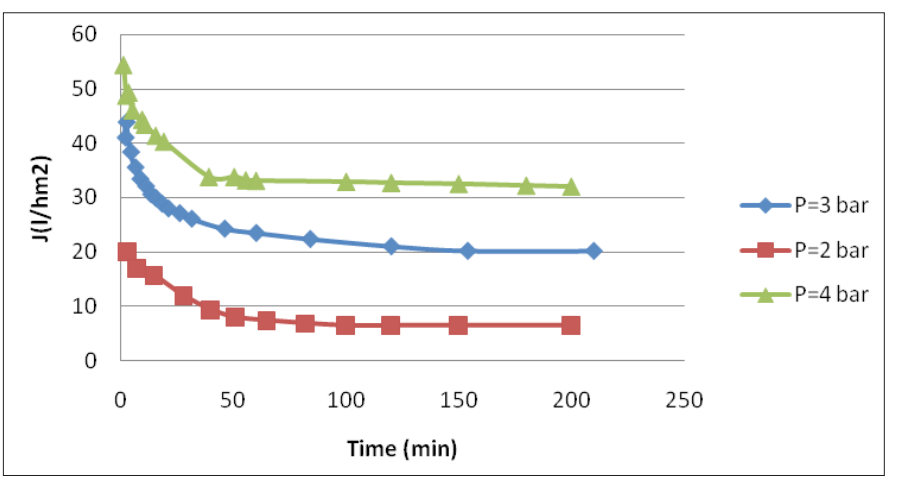

Fig. 14 Variation of the permeate flux with time of filtration

A similar behavior has been reported in literature for the same application [3, 39, 43]. The filtration flux evolution can be divided into two stages: first a sharp decrease followed by a stabilization phase. At the beginning of the filtration, it was assumed that a partial pore size reduction and the deposit of a loose particle layer at the surface take place by interaction of the melanin particles with the membrane material entailing the rapid decrease of the permeation flux. When this stage is completed, the filtration flux reaches a plateau that is only dependent on the TMP. It is also interesting to note that the constant permeate rate is reached more quickly when the pressure is high.

\subsubsection{Microfiltration performances}

Table 2 shows the main characteristics of the raw and treated effluents. The COD values of raw effluents from the production process ranged between 2000 and $3000 \mathrm{mgL}^{-1}$ with an average concentration of $2615 \mathrm{mgL}^{-1}$. The turbidity measured for the raw effluent presents a very high value which is about 335 NTU. As seen in the Table 2, a strong decrease of COD was obtained by filtration using kaolin membranes since the turbidity of the microfiltered sample was as low as $0.86,1.10$ and 2 NTU respectively for filtration at 2, 3 and 4 bar. On the other hand, the COD reduction was between 75 and $67 \%$ (from 699.5 to $862.6 \mathrm{mg} \mathrm{L}^{-1}$ with TMP from 2 to 4 bar). By contrast, the conductivity in permeate was in the range of $150-170 \mathrm{mS}$. $\mathrm{cm}^{-1}$ showing a slight decrease (25-35\%) indicating the contribution of the charged species retained by the membrane. 
Table 2 Characteristics of the effluent before and after filtration on kaolin membranes.

\begin{tabular}{lllll}
\hline & $\begin{array}{l}\text { Pressure } \\
(\text { bar })\end{array}$ & $\begin{array}{l}\text { Turbidity } \\
(\mathrm{NTU})\end{array}$ & $\begin{array}{l}\text { COD } \\
\left(\mathrm{mg} . \mathrm{L}^{-1}\right)\end{array}$ & $\begin{array}{l}\text { Conductivity } \\
\left(\mathrm{mS} . \mathrm{cm}^{-1}\right)\end{array}$ \\
\hline Raw effluents & 335 & 2615 & 204 \\
& 2 & 0.86 & 699.5 & 150 \\
Filtrate & 3 & 1.10 & 777.8 & 166 \\
TR $(\%)$ & 4 & 2 & 862.6 & 170 \\
\hline
\end{tabular}

TR : percentage reduction

Fig. 15 shows the noticeable discoloration of permeates compared to the feed. This observation is consistent with the strong decrease of turbidity since the black color of the feed solution is related to the presence of suspended melanin particles.
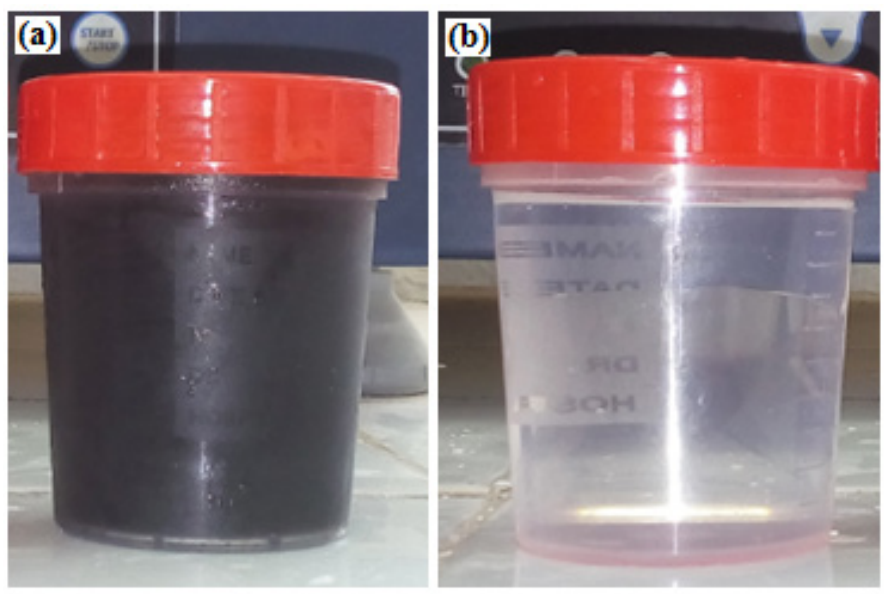

Fig. 15 Picture of the cuttlefish effluent: (a) before MF treatment and (b) after MF treatment.

Turbidity of permeate was found to get reduced by $99 \%$ when MF was carried out at a TMP of 3 bar, whereas COD was reduced by $70 \%$ and conductivity by almost $30 \%$. In fact, turbidity reductions were found to be more than the corresponding COD reduction on percentage basis. It can then be concluded that the kaolin MF membrane mainly retained the suspended matter (melanin) while the soluble fraction consisting of organic (macro) molecules and salts pass through the membrane. Such results are in agreement with the values given in the literature for inorganic MF membranes in similar applications (waste water treatment) [18, 29, 39, 43].

All studied parameters (turbidity, COD and conductivity) were found to increase by raising the TMP, which was attributed to a higher rejection at lower TMP. Melanin particles are smaller than the mean pore radius as mentioned above $[18,39]$ and they are retained by a partial pore blockage. It is then assumed that a pressure increase enables a very small amount of melanin particles to cross the membrane leading to a decrease of the membrane performance.
It appears from these results that the kaolin membranes can afford a highly satisfactory MF stage regarding the rejection of the suspended matter particularly as melanin particles is a valuable by-product that can be recovered.

\subsubsection{Evaluations of resistances}

The intrinsic membrane resistance, cake layer resistance and fouling resistance deduced from Eqs. (3), (4) and (5) for kaolin membrane are presented in Table 3.

The polarised layer resistance ( $\mathrm{Rp}$ ) was lower than the irreversible fouling resistance (Rf) and the major part of the total resistance was due to fouling $((\mathrm{Rp}+\mathrm{Rf}) / \mathrm{Rt})=66.67 \%)$. The reason for the high resistance, caused by the irreversible fouling, is that kaolin membrane presented large pores. Thus most particles are adsorbed on or plugged into the membrane pores $(\mathrm{Rf}>\mathrm{Rp})$.

Table 3 Resistance values for kaolin membrane.

\begin{tabular}{lllllll}
\hline $\begin{array}{l}\operatorname{Rt}\left(10^{12}\right) \\
\left(\mathrm{m}^{-1}\right)\end{array}$ & $\begin{array}{l}\mathrm{Rm}\left(10^{12}\right) \\
\left(\mathrm{m}^{-1}\right)\end{array}$ & $\begin{array}{l}\operatorname{Rp}\left(10^{12}\right) \\
\left(\mathrm{m}^{-1}\right)\end{array}$ & $\begin{array}{l}\mathrm{Rf}\left(10^{12}\right) \\
\left(\mathrm{m}^{-1}\right)\end{array}$ & $\begin{array}{l}\mathrm{Rm} / \mathrm{Rt} \\
(\%)\end{array}$ & $\begin{array}{l}\mathrm{Rp} / \mathrm{Rt} \\
(\%)\end{array}$ & $\begin{array}{l}\mathrm{Rf} / \mathrm{Rt} \\
(\%)\end{array}$ \\
\hline 54 & 18 & 5 & 31 & 33.33 & 9.27 & 57.4 \\
\hline
\end{tabular}

\section{Conclusions}

In this work, a comprehensive study on the fabrication and characterization of ceramic membrane from kaolin and starch mixtures were performed. The membranes were prepared by the extrusion procedure.

Ceramic membrane manufactured from kaolin and starch mixtures presented features of porosity (porous volume and average pore size) with values significantly higher than those elaborated from kaolin alone. It has also been found that the pore structure may be controlled by the sintering temperature.

The prepared membranes sintered at $1250^{\circ} \mathrm{C}$ offer a better mechanical strength (28 MPa compression strength), chemical stability ( $<5 \%$ weight loss in acidic media and negligible weight loss in acidic media), good porosity (27\%) and a higher average pore size $(0.73 \mu \mathrm{m})$.

The application of this membrane to the treatment of washing cuttlefish waters shows good performances in term of permeate flux and suspended matter (mainly melanin particles) rejection leading to a strong discoloration of the deep black feed.

\section{Acknowledgement}

Authors would like to thank European Institute of Membranes (IEM, UMR 5635 ENSCM/CNRS/UM) of Montpellier, France for their help to carry out the analysis. 


\section{References}

[1] Xu, L., Li, W., Lu, S., Wang, Z., Zhu, Q., Ling, Y. "Treating dyeing waste water by ceramic membrane in cross flow microfiltration." Desalination. 149, pp. 199-203. 2002. https://doi.org/10.1016/S0011-9164(02)00759-2

[2] Ebrahimi, M., Shams Ashaghi, K., Engel, L., Willershausen, D., Mund, P., Bolduan, P., Czermak, P. "Characterization and application of different ceramic membranes for the oil-field produced water treatment." Desalination. 245, pp. 533-540. 2009.

https://doi.org/10.1016/j.desal.2009.02.017

[3] Masmoudi, S., Ben Amar, R., Larbot, A., El Feki, H., Ben Salah, A., Cot, L. "Elaboration of inorganic microfiltration membranes with hydroxyapatite applied to the treatment of waste water from sea product industry." Journal of Membrane Science. 247, pp. 1-9. 2005.

https://doi.org/10.1016/j.memsci.2004.03.047

[4] Khemakhem, S., Ben Amar, R., Ben Hassen, R., Larbot, A., Medhioub, M., Ben Salah, A., Cot, L. "New ceramic membranes for tangential waste-water filtration." Desalination. 167, pp. 19-22. 2004. https://doi.org/10.1016/j.desal.2004.06.108

[5] Mahesh Kumar, S., Madhu, G. M., Sukumar, R. "Fouling behaviour, regeneration options and on-line control of biomass-based power plant effluents using micro porous ceramic membranes." Separation and $\mathrm{Pu}$ rification Technology. 57, pp. 25-36. 2007. https://doi.org/10.1016/j.seppur.2007.03.002

[6] Monash, P., Pugazhenthi, G. "Effect of TiO2 addition on the fabrication of ceramic membrane supports: a study on the separation of oil droplets and bovine serum albumin (BSA) from its solution." Desalination. 279, pp. 104-114. 2011.

https://doi.org/10.1016/j.desal.2011.05.065

[7] Han, J. H., Oh, E., Bae, B., Song, I. H. "The fabrication and characterization of sintered diatomite for potential microfiltration for applications." Ceramics International. 39, pp. 7641- 7648. 2013. https://doi.org/10.1016/j.ceramint.2013.02.102

[8] Zhu, H. J., Fan, Y., Xu, N. "Preparation and characterization of alumina membranes on capillary supports: effect of film-coating on crack-free membrane preparation." Chinese Journal of Chemical Engineering. 3, pp. 377-383. 2010.

https://doi.org/10.1016/S1004-9541(10)60234-0

[9] Qin, H. W., Peng, C., Lv, M., Wu, J. "Preparation and properties of high-purity porous alumina support at low sintering temperature." Ceramics International. 40, pp. 13741-13746. 2014.

https://doi.org/10.1016/j.ceramint.2014.05.044

[10] Li, G., Qi, H., Fan, Y., Xu, N. "Toughening macroporous alumina membrane supports with YSZ powders." Ceramics International. 35, pp. 1641-1646. 2009.

https://doi.org/10.1016/j.ceramint.2008.09.008

[11] Wang, Y. H., Tian, T. F., Liu, X. Q., Meng, G. Y. "Titania membrane preparation with chemical stability for very harsh environments Applications." Journal of Membrane Science. 280, pp. 261-269. 2006. https://doi.org/10.1016/j.memsci.2006.01.027

[12] Yoshino, Y., Suzuki, T., Nair, B. N., Taguchi, H., Itoh, N. "Development of tubular substrates, silica based membranes and membrane modules for hydrogen separation at high temperature." Journal of Membrane Science. 267, pp. 8-17. 2005.

https://doi.org/10.1016/j.memsci.2005.05.020

[13] Masmoudi, S., Larbot, A., El Feki, H., Ben Amar, R. "Elaboration and characterization of apatite based mineral supports for microfiltration and ultrafiltration membranes." Ceramics International. 33, pp. 337-344. 2007. https://doi.org/10.1016/j.ceramint.2005.10.001
[14] Saffaj, N., Persin, M., Younsi, S. A., Albizane, A., Cretin, M., Larbot, A. "Elaboration and characterization of microfiltration and ultrafiltration membranes deposited on raw support prepared from natural Moroccan clay: application to filtration of solution containing dyes and salts." $A p$ plied Clay Science. 31, pp. 110-119. 2006. https://doi.org/10.1016/j.clay.2005.07.002

[15] Palacio, L., Bouzerdi, Y., Ouammou, M., Albizane, A., Bennazha, J., Hernández, A., Calvo, J. I. "Ceramic membranes from Moroccan natural clay and phosphate for industrial water treatment." Desalination. 245, pp. 501-507. 2009.

https://doi.org/10.1016/j.desal.2009.02.014

[16] Jana, S., Purkait, M. K., Mohanty, K. "Preparation and characterization of low-cost ceramic microfiltration membranes for the removal of chromate from aqueous solutions." Applied Clay Science. 47, pp. 317-324. 2010. https://doi.org/10.1016/j.clay.2009.11.036

[17] Ayadi, S., Jedidi, I., Rivallin, M., Gillot, F., Lacour, S., Cerneaux, S., Cretin, M., Ben Amar, R. "Elaboration and characterization of new conductive porous graphite membranes for electrochemical advanced oxidation processes." Journal of Membrane Science. 446, pp. 42-49. 2013. https://doi.org/10.1016/j.memsci.2013.06.005

[18] Khemakhem, M., Khemakhem, S., Ayedi, S., Ben Amar, R. "Study of ceramic ultrafiltration membrane support based on phosphate industry subproduct: application for the cuttlefish conditioning effluents treatment." Ceramics International. 37, pp. 3617-3625. 2011.

https://doi.org/10.1016/j.ceramint.2011.06.020

[19] Khemakhem, M., Khemakhem, S., Ayedi, S., Cretin, M., Ben Amar, R. "Development of an asymmetric ultrafiltration membrane based on phosphates industry sub-products." Ceramics International. 41, pp. $10343-$ 10348. 2015.

https://doi.org/10.1016/j.ceramint.2015.05.101

[20] Bouzerara, F., Harabi, A., Achour, S., Labrot, A. "Porous ceramic supports for membranes prepared from kaolin and doloma mixtures." Journal of the European Ceramic Society. 26, pp. 1663-1671. 2006.

https://doi.org/10.1016/j.jeurceramsoc.2005.03.244

[21] Boudaira, B., Harabi, A., Bouzerara, F., Condom, S. "Preparation and characterization of microfiltration membranes and their supports using kaolin (DD2) and CaCO3." Desalination and Water Treatment. 9, pp. 142-148. 2009.

https://doi.org/10.5004/dwt.2009.764

[22] Bouzerara, F., Harabi, A., Condom, S. "Porous ceramic membranes prepared from kaolin." Desalination and Water Treatment. 12, pp. 415-419. 2009.

https://doi.org/10.5004/dwt.2009.1051

[23] Harabi, A., Guechi, A., Condom, S. "Production of supports and filtration membranes from Algerian kaolin and limestone." Procedia Engineering. 33, pp. 220-224. 2012.

https://doi.org/10.1016/j.proeng.2012.01.1197

[24] Harabi, A., Zenikheri, F., Boudaira, B., Bouzerara, F., Guechi, A., Foughali, L. "A new and economic approach to fabricate resistant porous membrane supports using kaolin and $\mathrm{CaCO}_{3}$." Journal of the European Ceramic Society. 34, pp. 1329-1340. 2014. https://doi.org/10.1016/j.jeurceramsoc.2013.11.007

[25] Tewari, P. K., Singh, R. K., Batra, V. S, Balakrishnan, M. "Membrane bioreactor (MBR) for waste water treatment: filtration performance evaluation of low cost polymeric and ceramic membranes." Separation and Purification Technology. 71, pp. 200-204. 2010. https://doi.org/10.1016/j.seppur.2009.11.022

[26] Dong, Y., Liu, X., Ma, Q., Meng, G. "Preparation of cordierite-based porous ceramic micro-filtration membranes using waste fly ash as the main raw materials." Journal of Membrane Science. 285, pp. 173-181. 2006. https://doi.org/10.1016/j.memsci.2006.08.032 
[27] Cao, J., Dong, X., Li, L., Dong, Y., Hampshire, S. "Recycling of waste fly ash for production of porous mullite ceramic membrane supports with increased porosity." Journal of the European Ceramic Society. 34, pp. 3181-3194. 2014.

https://doi.org/10.1016/j.jeurceramsoc.2014.04.011

[28] Jedidi, I., Khemakhem, S., Larbot, A., Ben Amar, R. "Elaboration and characterization of fly ash based mineral supports for microfiltration and ultrafiltration membranes." Ceramics International. 35, pp. 2747-2753. 2009. https://doi.org/10.1016/j.ceramint.2009.03.021

[29] Jedidi, I., Saïdi, S., Khemakhem, S., Larbot, A., Elloumi-Ammar, N., Fourati, A., Ben Salah, A., Ben Amar, R. "Elaboration of new ceramic microfiltration membranes from mineral coal fly ash applied to waste water treatment." Journal of Hazardous Materials. 172, pp. 152-158. 2009. https://doi.org/10.1016/j.jhazmat.2009.06.151

[30] Lee, S. H., Chung, K. C., Shin, M. C., Dong, J. I., Lee, H. S., Auh, K. H. "Preparation of ceramic membrane and application to the cross flow microfiltration of soluble waste oil." Materials Letters. 52, pp. 266-271. 2002.

https://doi.org/10.1016/S0167-577X(01)00405-0

[31] Oh, H. K., Takizawa, S., Ohgaki, S., Katayama, H., Oguma, K., Yu, M. J. "Removal of organics and viruses using hybrid ceramic, MF system without draining PAC." Desalination. 202, pp. 191-198. 2007. https://doi.org/10.1016/j.desal.2005.12.054

[32] Nandi, B. K., Das, B., Uppaluri, R., Purkait, M. K. "Microfiltration of mosambi juice using low cost ceramic membrane." Journal of Food Engineering. 95, pp. 597-605. 2009.

https://doi.org/10.1016/j.jfoodeng.2009.06.024

[33] Rai, P., Rai, C., Majumdara, G. C., DasGupta, S., De, S. "Resistance in series model for ultrafiltration of mosambi (Citrus sinensis (L.) Osbeck) juice in a stirred continuous mode." Journal of Membrane Science. 283, pp. 116-122. 2006.

https://doi.org/10.1016/j.memsci.2006.06.018

[34] Vladisavljevi, G. T., Vukosavljevi, P., Bukvi, B. "Permeate flux and fouling resistance in ultrafiltration of depectinized apple juice using ceramic membranes." Journal of Food Engineering. 60, pp. 241-247. 2003. https://doi.org/10.1016/S0260-8774(03)00044-X

[35] Sahnoun, R. D., Bouaziz, J. "Sintering characteristics of kaolin in the presence of phosphoric acid binder" Ceramics International. 38, pp.1-7. 2012. https://doi.org/10.1016/j.ceramint.2011.06.058
[36] Boulmokh, A., Berredjem, Y., Guerfi, K., Gheid, A. "Kaolin from Djebel Debbagh Mine, Guelma, Algeria." Research Journal of Applied Sciences. 2 (4), pp. 435-440. 2007. URL: http://medwelljournals.com/ abstract/?doi=rjasci.2007.435.440

[37] Harrabi, A., Bouzerara, F., Condom, S. "Preparation and characterization of tubular membrane supports using centrifugal casting." Desalination and Water Treatment. 6, pp. 222-226. 2009.

https://doi.org/10.5004/dwt.2009.646

[38] Palumbo, A. "Melanogenesis in the ink gland of Sepia officinalis." Pigment Cell Research. 16, pp. 517-522.2003. https://doi.org/10.1034/j.1600-0749.2003.00080.x

[39] Masmoudi, S., Larbot, A., El Feki, H., Ben Amar, R. "Elaboration and properties of new ceramic microfiltration membranes from natural and synthesised apatite." Desalination. 190, pp. 89-103. 2006. https://doi.org/10.1016/j.desal.2005.03.097

[40] Issaoui, M., Bouaziz, J., Fourati, M. "Elaboration of membrane ceramic supports using aluminium powder." Desalination and Water Treatment. 53, pp. 1037-1041. 2015. https://doi.org/10.1080/19443994.2013.871341

[41] Fakhfakh, S., Baklouti, S., Baklouti, S., Bouaziz, J. "Elaboration and characterization of low cost ceramic support membrane." Advances in Applied Ceramics. 108, pp. 31-38. 2010. https://doi.org/10.1179/174367609X422234

[42] Rekik, S., Bouaziz, J., Deratani, A., Baklouti, S. "Development of an asymmetric ultrafiltration membrane from naturally-occurring kaolin clays: Application to the cuttlefish effluents treatments." International Journal of Membrane Science and Technology. 6(3), 1000159, 2016. https://doi.org/10.4172/2155-9589.1000159

[43] Jedidi, I., Saïdi, S.,Khemakhem, S., Larbot, A., Elloumi-Ammar, N., Fourati, A., Charfi, A., Ben Amar, R. "New ceramic microfiltration membranes from mineral coal fly ash." Arabian Journal of Chemistry. 2, pp. 31-39. 2009.

https://doi.org/10.1016/j.arabjc.2009.07.006 